\title{
Model for Selection of the Best Location Based on Fuzzy AHP and Hurwitz Methods
}

\author{
Slavko Arsovski, ${ }^{1}$ Gordana Todorovic, ${ }^{2}$ Zorica Lazić, ${ }^{1}$ Zora Arsovski, ${ }^{3}$ \\ Nikolina Ljepava, ${ }^{4}$ and Aleksandar Aleksic ${ }^{1}$ \\ ${ }^{1}$ Faculty of Engineering, University of Kragujevac, Jovana Cvijića bb, 34000 Kragujevac, Serbia \\ ${ }^{2}$ Public Company "Parking Servis Kragujevac", Vojislava Kalanovica bb, 34000 Kragujevac, Serbia \\ ${ }^{3}$ Faculty of Economics, University of Kragujevac, Djure Pucara Starog 3, 34000 Kragujevac, Serbia \\ ${ }^{4}$ American University in the Emirates, Academic City, Dubai, UAE
}

Correspondence should be addressed to Aleksandar Aleksic; aaleksic@kg.ac.rs

Received 27 December 2016; Revised 20 May 2017; Accepted 25 July 2017; Published 24 September 2017

Academic Editor: Anna M. Gil-Lafuente

Copyright (C) 2017 Slavko Arsovski et al. This is an open access article distributed under the Creative Commons Attribution License, which permits unrestricted use, distribution, and reproduction in any medium, provided the original work is properly cited.

\begin{abstract}
The problem of evaluation and selection of parking lots is a part of significant issues of public transport management in cities. As population expands as well as urban areas, solving the mentioned issues affects employees, security and safety of citizens, and quality of life in long-time period. The aim of this paper is to propose a multicriteria decision model which includes both quantitative and qualitative criteria, which may be of either benefit or cost type, to evaluate locations. The criteria values and the importance of criteria are either precise or linguistic expressions defined by trapezoidal fuzzy numbers. The human judgments of the relative importance of evaluation criteria and uncertain criteria values are often vague and cannot be expressed by exact precise values. The ranking of locations with respect to all criteria and their weights is performed for various degrees of pessimistic-optimistic index. The proposed model is tested through an illustrative example with real life data, where it shows the practical implications in public communal enterprises.
\end{abstract}

\section{Introduction}

Rapid and constant increase of the number of city residents all over the world, in the developed as well as in the developing countries, and enhanced dynamics of living result in issues emerging in communal services, especially in the domain of stationary transport and parking [1]. Nonadequate strategies of management may cause pollution of the environment, increased load of traffic flow, reduction of the safety of traffic, and so forth.

According to the results of good practice, it is known that the zonal billing system is one of the parking strategies whose implementation is the best way to solve the mentioned issue. This parking strategy may be improved by building above ground parking garages. Construction of these demands certain investment costs but at the same time, it impacts competitiveness and prosperity of the city in the long run. With respect to these facts, it can be said that the problem of assessment and ranking of possible sites for construction of above ground parking garages may be one of the major tasks of the local government. The solution of this problem may be propagated into economic and political way of local government's functioning.

Motivation for this research comes from the fact that there are no research papers which treat selection of land suitable for building above ground parking garages. In practice, the solution for the treated problem is obtained by using appropriate methods, such as Delphi technique, experts' opinion, panel discussion, and tree analysis [2]. However, each solution obtained by applying mentioned methods is burdened by subjective opinions of decision makers in some degree.

The selection of locations for building of above ground parking garages depends on economic, environmental, and legislative issues as well as other demands by different 
stakeholders. It can be assumed that the considered problem can be stated as multicriteria decision making (MCDM) problem with some uncertain data.

By using methodology based on fuzzy sets, it is hard to believe that it is possible to obtain the solution of the treated problem by relying on single criterion [3]. Consideration of the problem situations as single criterion decision making problem presents merely an oversimplification of the actual nature of the problem; so consequently, it can lead to unrealistic decision. These authors suggest MCDM which is a powerful tool widely used for evaluating different problems with respect to multiple, usually conflicting criteria. There are no rules or suggestions on how the evaluation criteria and which MCDM method should be chosen.

In conventional AHP [4], the ratings of the values of the existing variables are described by crips numbers. The usage of discrete scale is simple and easy, but it is not sufficient considering uncertainty associated with the mapping of one's perception to a number [5]. Decision makers express their judgments far better by using linguistic expressions than by representing them in terms of precise numbers. The more suitable way for human way of thinking is to proceed with using linguistic variables which are introduced by [6], instead of precise numbers. The fuzzy linguistic approach based on the fuzzy set theory has unconstrained boundary between true and false and it is widely used approach for modelling the linguistic variables $[7,8]$. Most of these approaches provide a priori fixed predefined linguistic expressions that decision makers are constrained to use for expressing their preferences in a simple way. Using simple fuzzy linguistic approaches composed of a single term is not always suitable to represent the real preferences of the decision makers.

The objective of this research may be interpreted as the development of the new model which includes integration of the fuzzy Analytic Hierarchical Process (FAHP) and Hurwitz method. The decision makers may assess the relative importance in smooth and precise manner if they analyze each pair of criteria separately (by analogy to AHP) rather than to make an analysis of all criteria in the same time. Hurwitz method has the same mathematical base as many other MCDM methods. The procedure for finding the optimal solution which is suggested in Hurwitz method is significantly less complex compared to the procedures developed in other MCDM methods. As it may be noticed, by application of Hurwitz method, the optimal solutions may be obtained in short period. Those solutions are precise enough so it may be assumed that this method is suitable for solving problems that are generated in real life environment. By using the proposed model, the best location for building above ground parking garage is obtained. It may be assumed that the decision made in this way is less hampered by subjective opinions of the decision makers, so it is more precise compared to decisions derived from qualitative methods.

The main contribution of the paper is application of scientific approach in decision making process in public enterprises. In this way, effectiveness of stationary transport in urban areas is significantly increased which is further propagated to possible enhancement of local government's effectiveness.
The paper is organized in the following way: a fuzzification of AHP method, which can be found in the literature, is summarized and analysed in Section 2. Section 3 presents the proposed model to deal with fuzzy data to support the decision making. The proposed model is illustrated by real-life data in Section 4. At last, a discussion of research, conclusions, and future steps are presented in Section 5.

\section{Materials and Methods}

In the literature, there are many papers in which selecting alternative problem in presence of uncertainty is considered. Uncertainties in the relative importance of criteria, alternative values, at the same time are described by linguistic expressions which are modelled by type- 1 fuzzy numbers such as TFNs $[9,10]$, TrFNs [11-13], or the intuitionistic fuzzy sets. Many authors suggest that the uncertainties can be modelled in a better way by using the type- 2 fuzzy numbers. The domains of type- 1 fuzzy numbers used are defined in real line into different intervals. For instance, common measurement can be used (Ćurčić, 2011). Kelemenis and Askounis [14] have used interval [1-10], and domain of fuzzy numbers is defined by interval $[0-10][10,11,15]$. Modelling of different uncertainties by TFNs or TrFNS is performed since they have the advantage of simplicity over other types of fuzzy numbers. Curves of higher order of membership functions lead to increased complexness of computation but at the same time they do not result in increased correctness of solution.

Selecting the best location with respect to many criteria which are defined either as benefit criteria (i.e., the larger the criterion value, the greater the preference) or cost criteria (i.e., the smaller the criterion value, the greater preference) can be performed by using the proposed methods [15, 16] (Ćurčić, 2011).

In the papers [15, 16] (Ćurčić, 2011), calculation of the weights vector of evaluation criteria is often based on fuzzy AHP framework. FAHP enables mapping of human perception by a particular number or a ratio and we are also able to consider the vagueness in the decision making process. The elements of fuzzy pairwise comparison matrix should be described by linguistic expressions which are modelled by triangular fuzzy numbers (TFNs) [10, 17]. Also, in the literature there are papers where the elements of fuzzy pairwise comparison matrix of the criteria relative importance are modelled by trapezoidal fuzzy numbers (TrFNs) $[18,19]$. Handling of FAHP can be performed by using two approaches which are proposed in the literature.

By using Chang's extent analysis method [20], the synthetic extent value of the pairwise comparison is calculated. The obtained normalized weights vector of criteria is not a fuzzy number [21]. This method is widely used in the literature $[10,17]$. It has been shown that the extent analysis method cannot estimate the true weights from a fuzzy comparison matrix and has led to quite a number of misapplications. However, in the literature, this approach has widely been used because it does not involve cumbersome mathematical operations and it has the ability to capture the vagueness of the human thinking style. 
In the method for handling of FAHP proposed by $\mathrm{Wu}$ et al. [22], the criteria weights are derived from the fuzzy preference rations; thus the developed approach allows a more reasonable description of the decision making process and reflects the thinking style of a human.

In this paper, an approach for handling fuzzy pairwise comparison [22] is used, by analogy with Tadić et al. [18] and Macuzić et al. [19].

In the FAHP framework, the alternative values may be described as precise numbers [15], uncertain numbers [23], and either precise or imprecise numbers at the same time (Ćurčić, 2011).

Assessment of the criteria relative importance is performed by direct way and modelled by TFNs. Fuzzy rating of the relative importance of considered criteria is stated as fuzzy group decision making problem. The assessed values are modelled by type-2 fuzzy sets. Aggregation of different opinions of decision makers into group consensus is achieved by using fuzzy averaging method.

As a unique problem, the ranking of considered locations may be performed by using AHP method [24, 25], fuzzy AHP [23], fuzzy TOPSIS [15, 16], adopted Hurwitz method (Ćurčić, 2011), and so forth. Compared to other employed multicriteria decision making methods, it may be assumed that Hurwitz method is computationally attractive which is very important for practitioners. In the literature, papers that employ adopted Hurwitz criterion for ranking issues can be found [26-28].

The relative importance of criteria in these papers is described by discrete fuzzy numbers $[26,27]$. The weights vector is given by using the procedure for calculating measure of belief that any discrete fuzzy number is greater than or equal to other discrete fuzzy numbers (Petrović and Petrović, 2001). Ćurčić et al. [28] suggested that the relative importance of evaluation criteria may be obtained by using fuzzy AHP [20].

In this paper, the relative importance of criteria is stated by fuzzy pairwise comparison matrix whose elements are modelled by TrFNs. The weights vector is calculated by using fuzzy geometric operator [22], and its elements are modelled by TrFNs.

Petrovic and Petrovic [27] suggested a new normalization procedure for uncertain criteria values. As uncertain criteria in the considered problem are of benefit type, authors suggest that domains of TrFNs should be defined by the interval [0-1] $[12,18]$. In this manner, the calculation volume is decreased. Transformation of the linguistic criteria values is achieved by linear normalization procedure [29] in [26, 28].

In this paper, crisp criteria are normalized by using vector normalization procedure.

Also, in this paper, the weighted normalized fuzzy decision matrix is constructed. The value of elements of these matrices are described by TrFNs. By using the defuzzification procedure, the fuzzy decision matrix is mapped into decision matrix. Selecting the best alternative with respect to all criteria and their weights is performed by adopted Hurwitz method proposed by the analyzed papers. As it is known, one of the shortages of this method is the stability of the solution, which depends on the optimistic-pessimistic coefficient values. In this paper, the stability of the proposed solution is tested.

\section{The Proposed Model}

Increasing population in urban areas, rapid development of industry, and the delivery of different business activities result in delays due to traffic congestion, pollution of the environment, increase in the number of traffic accidents, and so forth. Solving this issue may be overcome through the enhancement of traffic infrastructure. One of the improvement strategies is the construction of above ground parking garages on the existing parking lots. The application of this strategy demands certain economic investment by local government which expects the return of the investment in the reasonable period of time. Therefore, the ranking and selection of existing parking lots for construction of above ground parking garages is one of the significant tasks for the management in any public communal enterprise. In this paper, a new integrated fuzzy multicriteria model for ranking of parking lots that are suitable for construction of above ground parking garage is proposed (Figure 1). It can be assumed that the rank of parking lots obtained by using the proposed model increases the correctness of the solution.

For the purpose of writing appropriate programming code that will be used for computation of the proposed model, the pseudocode is provided below.

Input. The input is evaluation criteria, fuzzy rating of the relative importance of each pair of criteria, crisp evaluation criteria values, and fuzzy rating of uncertain evaluation criteria values.

Output. The output is fuzzy decision matrix, decision matrix, and optimal solution.

Procedure

(1) Get evolution criteria

(2) Load fuzzy rating of the relative importance of each pair of criteria

(3) Calculate fuzzy pair-wise comparison matrix consistency

(4) If fuzzy pair-wise comparison matrix consistency $\geq$ 0.1

(5) Go to step (2)

(6) Else calculate weights vector of evaluation criteria

(7) Load crisp evaluation criteria values

(8) Calculate normalized crisp criteria values

(9) Load fuzzy rating of uncertain evaluation criteria values

(10) Calculate fuzzy aggregated uncertain criteria values

(11) Calculate fuzzy decision matrix 


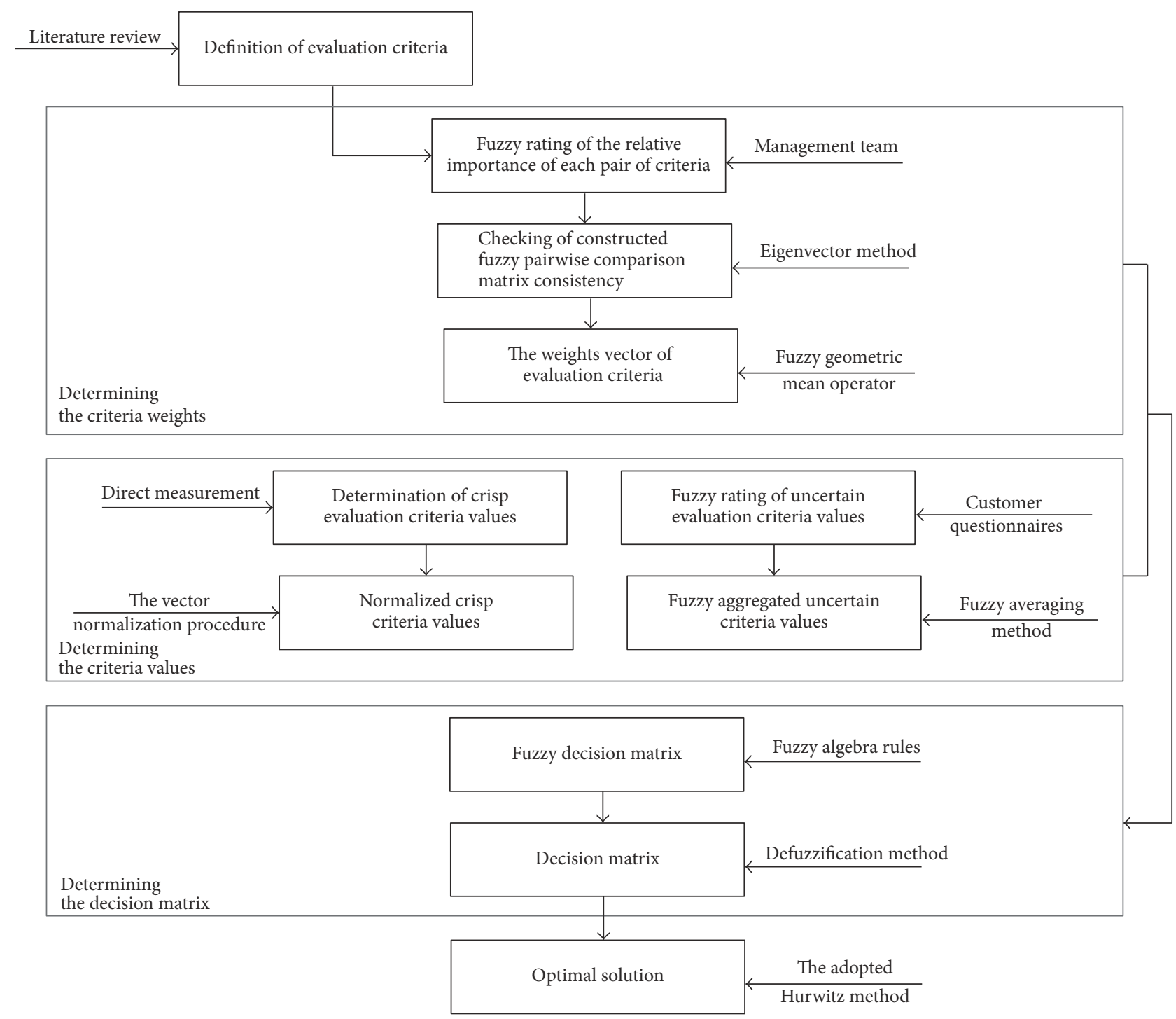

Figure 1: The evaluation framework.

(12) Calculate decision matrix

(13) Calculate optimal solution

(14) Stop

The big $O$ notation may be employed to compute the time complexity. By applying big $O$ notation, the calculation of the worst case may be conducted. This calculation is articulated in terms of the time the algorithm takes to accomplish its function.

The first computation step is to set fuzzy pairwise comparison matrix of the relative importance of criteria which are mutually independent. The fuzzy pairwise comparison matrix is transformed to the pairwise comparison matrix. The eigenvector is used to find consistency coefficient of set matrix. The time complexity of finding the eigenvector is $O\left(n^{3}\right)[30]$.
Finding the weighted normalized fuzzy decision matrix includes several multiplication operations between each normalized criteria value and the corresponding weight in the unweighted fuzzy decision matrix. The one iteration loop is used for each multiplication operation, so this implies that the time complexity is $O(n)$ for each single operation and the time complexity for the whole weighed normalized fuzzy decision matrix is $O\left(n^{2}\right)$.

3.1. Selection of Evaluation Criteria. The evaluation criteria are defined by the management team (main manager, technical manager, and development manager). Their judgments should take into consideration the profitability of the enterprise, with respect to the legislation in the domain of environmental protection and in the domain of urban organization of the city. Moreover, the evaluation criteria associated with the different requirements of clients should be embedded in 
the model. Thus, apart from a number of generic criteria, many specific criteria should be considered case by case. For instance, different criteria take into account evaluation of the parking for passenger vehicles and the commercial vehicles. Formally, set of evaluation criteria can be formally presented by set $\kappa=\{1, \ldots, k, \ldots, K\}$. The index for evaluation criterion is denoted as $k, k=1, \ldots, K$, and the total number of treated criteria is denoted as $K$. The criteria used in this paper are proposed by Jelokhani-Niaraki and Malczewski [31]: (1) adjacent population to a candidate site (this is the number of people residing within 500 meters of a candidate site); (2) land size (this is the total area of a candidate site); (3) land cost (this value is obtained by multiplying the land size and the land cost per square meter); (4) distance to roads (distance to main road may be observed as the nearest distance from a candidate parking lot site to a main road; main roads cover community's main shopping areas with various amenities); (5) average distance to recreation centers (recreation centers include sport, leisure, and entertainment centers (e.g., cinemas, museums, and visitor attractions)); (6) average distance to administrative centers (these centers include large public buildings, administrative services centers, educational centers, community centers, etc.); (7) average distance to commercial centers (this is associated mainly with retail shopping centers); (8) average distance to transportation stations (this option includes transportation stations, such as subway stations or bus terminals which are essential for multimodal transportation).

In general, existing parking lots are usually suitable for construction of above ground parking garage. In practice, the management team should define a set of possible locations that are suitable for construction of above ground parking garage. Management team makes the decision with respect to business strategy and valid urban plans. Formally, set of possible locations can be formally presented by set $\iota=$ $\{1, \ldots, i, \ldots, I\}$. The index for a parking lot location is denoted as $i, i=1, \ldots, I$, and the total number of parking lot locations which are suitable for above ground parking garage is denoted as $I$.

3.2. Choice of Appropriate Linguistic Expressions for the Assessment of the Relative Importance of Criteria and the Rating of the Parking Lots. An assessment of relative importance of criteria and their values takes place in a complex environment where uncertain and vague knowledge has to be considered. More sensible decision maker's assessments may be achieved if decision makers use linguistic expressions instead of precise values. There are several developed theories in the mathematical area which may be employed for modelling impreciseness and uncertainties. Particularly, the linguistic variables should be adequately represented by using the fuzzy set theory. Fuzzy numbers generalize the membership function in allowing all values between zero and one, location in the universe of discourse, and granularity. There is no guideline how to determine location in the universe of discourse and granularity of fuzzy numbers. Fuzzy numbers habitually may be presented symmetrically on the proposed scale. The lower bound, upper bound, and modal value of any fuzzy number are determined in compliance with decision makers' experience and knowledge.

The numbers of linguistic variables which are assigned to the existing uncertainties depend on the type and size of the problem and the opinion of the management team. In this paper, with respect to the type and size of the considered problem, and the opinion of the decision makers, it is assumed that the five linguistic expressions at the most could be assigned to the existing linguistic variables.

The linguistic variables that describe the relative importance of evaluation criteria are modelled by TrFNs the domain of which is defined on the common measurement scale [4] and presented as follows:

$$
\begin{aligned}
& \text { very low importance, } \widetilde{W}_{1}=(x ; 1,1,1.5,2) \\
& \text { low importance, } \widetilde{W}_{2}=(x ; 1.5,2,3,3.5) \\
& \text { fairly moderate importance, } \widetilde{W}_{3}=(x ; 2.5,3,4,4.5) \\
& \text { moderate importance, } \widetilde{W}_{4}=(x ; 4,4.5,5.5,6) \\
& \text { moderate to high importance, } \widetilde{W}_{5}=(x ; 5.5,6,7,7.5) \\
& \text { high importance, } \widetilde{W}_{6}=(x ; 7,7.5,8.5,9) \\
& \text { very high importance, } \widetilde{W}_{7}=(x ; 8,8.5,9,9) .
\end{aligned}
$$

All uncertain criteria are of benefit type and their values are described by five linguistic expressions which are modelled by TrFNs. It is assumed that the domains of these TrFNs belong to the interval [0-1]. The values 0 and 1 denote the lowest and the highest value of considered criteria, respectively. Specifically, these linguistic expressions are modelled by TrFNs as follows:

$$
\begin{aligned}
& \text { very low }(y ; 0,0,0.1,0.15) \\
& \text { low }(y ; 0.15,0.25,0.3,0.45) \\
& \text { moderate }(y ; 0.35,0.45,0.55,0.65) \\
& \text { high }(y ; 0.55,0.65,0.75,0.85) \\
& \text { very high }(y ; 0.75,0.9,1,1) .
\end{aligned}
$$

3.3. Determining of the Criteria Weights. The fuzzy pairwise comparison matrix of the relative importance of criteria is stated. The elements of this matrix are defined as the relative importance evaluation criterion $k, k=1, \ldots, K$ over evaluation criterion $k^{\prime}, k^{\prime}=1, \ldots, K$. Values of these elements are presented by TrFNs. If the strong relative importance of evaluation criterion $k^{\prime}$ over evaluation criterion $k$ holds, then the pairwise comparison scale can be represented by the TFN $\widetilde{W}_{k k^{\prime}}=\left(\widetilde{W}_{k^{\prime} k}\right)^{-1}=\left(1 / u_{k^{\prime} k}, 1 / m_{k^{\prime} k}, 1 / n_{k^{\prime} k}, 1 / l_{k^{\prime} k}\right)$ (according to (5)). If evaluation criteria $k$ and $k^{\prime}, k, k^{\prime}=1, \ldots, K$ have equal relative importance, then the value of the elements of fuzzy pairwise matrix of the relative importance of evaluation criteria can be represented by a single point 1 which is a $\mathrm{TrFN}$ $(1,1,1,1)$.

The management team assess the relative importance of those pairs of criteria which are placed above the main diagonal (by analogy to conventional AHP). As decision makers may make errors in judgments, it is necessary to 
check if it is possible to define domination in this manner. It may be conducted in the following manner. Firstly, the values of elements of constructed fuzzy pairwise decision matrix of the relative importance of criteria are defuzzified by procedure proposed by Zimmermann (2001). In this way, the constructed fuzzy pairwise decision matrix is mapped into pairwise decision matrix with features that denote positive and reciprocity values compared to the main diagonal. Secondly, consistency of pairwise comparison matrix should be performed. In the literature, there are several methods for handling scales in the AHP (Saaty, 1990) [4]. One of them, which is the frequently used and theoretically defined, is the eigenvalue method (EM). By using EM, the consistency index (CI) can be calculated, and it can provide a way of measuring how many errors have been produced when the assessment was performed. The consistency index is calculated as ratio of the consistency ratio (CR) and random index (RI), which are calculated according to the following expressions:

$$
\mathrm{CR}=\frac{\lambda_{\max }-n}{n-1}
$$

where $\lambda_{\max }$ is the principal eigenvalue of the pairwise comparison matrix; the computation of this value is accomplished by raising the pairwise comparison matrix to a sufficiently larger power. Size of pairwise comparison matrix is denoted as $n$.

Value of RI depends on the size of pairwise matrix. These values for matrices of various sizes are contained in [4]. If CI is equal to or less than 0.1 it can be assumed that assessment mistakes made are acceptable, so determining of the weights vectors of evaluation criteria should be based on the stated fuzzy pairwise comparison matrix. In this paper, handling of uncertainties occurs if performed by procedure in Wu et al. [22], such as order

$$
\begin{aligned}
& \alpha_{k}=\left[\prod_{k=1}^{K} l_{k k^{\prime}}\right]^{1 / K}, \\
& \beta_{k}=\left[\prod_{k=1}^{K} m_{k k^{\prime}}\right]^{1 / K}, \\
& \chi_{k}=\left[\prod_{k=1}^{K} n_{k k^{\prime}}\right]^{1 / K}, \\
& \delta_{k}=\left[\prod_{k=1}^{K} u_{k k^{\prime}}\right]^{1 / K}, \\
& \alpha=\sum_{k=1}^{K} \alpha_{k}, \\
& \beta=\sum_{k=1}^{K} \beta_{k}, \\
& \chi=\sum_{k=1}^{K} \chi_{k},
\end{aligned}
$$

$$
\chi=\sum_{k=1}^{K} \delta_{k}
$$

Then the weights vector of evaluation criteria can be represented in matrix form, $\widetilde{W}=\left[\widetilde{w}_{k}\right]_{1 \times K}$. The elements of this vector are given as

$$
\begin{aligned}
\widetilde{w}_{k} & =\left(x ; \alpha_{k} \cdot \delta^{-1}, \beta_{k} \cdot \chi^{-1}, \chi_{k} \cdot \beta^{-1}, \delta_{k} \cdot \alpha^{-1}\right) \\
& =\left(x ; l_{k}, m_{k}, n_{k}, u_{k}\right)
\end{aligned}
$$

where

$$
\begin{aligned}
& l_{k}=\alpha_{k} \cdot \delta^{-1} ; \\
& m_{k}=\beta_{k} \cdot \chi^{-1} ; \\
& n_{k}=\chi_{k} \cdot \beta^{-1}, \\
& u_{k}=\delta_{k} \cdot \alpha^{-1} .
\end{aligned}
$$

3.4. Constructing of the Weighted Normalized Fuzzy Decision Matrix. The weighted normalized fuzzy decision matrix denoted by $\widetilde{D}$ is given when the weight of each criterion is incorporated into the normalized fuzzy decision matrix and shown as

$$
\widetilde{D}=\left[\widetilde{d}_{i k}\right]_{I \times K}^{T}
$$

where $\widetilde{d}_{i k}$ is value of the weighted normalized fuzzy decision matrix. The procedure for calculation of these values is presented in the following text.

With respect to definitions of considered evaluation criteria, it may be clearly noticed that some of them are measurable and the rest are uncertain. Let $K^{\prime}$ be the total number of crisp criteria, and $v_{i k}$ should be the value of crisp criterion $k, k=1, \ldots, K^{\prime}$, for parking lot location $i, i=$ $1, \ldots, I$. These crisp values are presented by different unit dimensions. By using the normalization procedure, these values, $v_{i k}$, are mapped into $r_{i k}$ which belong to the interval [0-1]. The value 0 and value 1 denote the smallest and the greatest value of criterion $k, k=1, \ldots, K^{\prime}$, for parking area $i, i=1, \ldots, I$, respectively. The normalized values of crisp criteria are comparable. In this paper, the vector normalization procedure is used [32]:

(a) for benefit type criterion

$$
r_{i k}=\frac{v_{i k}}{\sqrt{\sum_{i=1}^{I} v_{i k}^{2}}},
$$

(b) for cost type criterion

$$
r_{i k}=\frac{1 / v_{i k}}{\sqrt{\sum_{i=1}^{I}\left(1 / v_{i k}\right)^{2}}} .
$$


The weighted normalized crisp criteria values, $\tilde{d}_{i k}$, are TrFNs, such as

$$
\tilde{d}_{i k}=\widetilde{w}_{k} \cdot r_{i k}
$$

where

$$
\tilde{d}_{i k}=\left(y ; l_{k} \cdot r_{i k}, m_{k} \cdot r_{i k}, n_{k} \cdot r_{i k}, u_{k} \cdot r_{i k}\right)
$$

The values of uncertain criteria are determined according to results of the questionnaire where random customers gave their answers. Fuzzy rating of each customer is denoted by TrFNs, $\widetilde{r}_{i k}^{e}$. As the domains of these TrFNs are defined by the interval [0-1], it may be considered that these values are normalized. The aggregated fuzzy values of customers' ratings $\widetilde{r}_{i k}$ are calculated by using fuzzy averaging method, so

$$
\begin{aligned}
\widetilde{r}_{i k} & =\frac{1}{E} \cdot \widetilde{r}_{i k}^{e}=\frac{1}{E} \cdot\left(y ; \sum_{e=1}^{E} l_{i k}^{e}, \sum_{e=1}^{E} m_{i k}^{e}, \sum_{e=1}^{E} n_{i k}^{e}, \sum_{e=1}^{E} u_{i k}^{e}\right) \\
& =\left(y ; l_{i k}, m_{i k}, n_{i k}, u_{i k}\right)
\end{aligned}
$$

where $E$ is the total number of customers who took part in the questionnaire and $e$ is index of customer, $e=1, \ldots, E$.

The weighted normalized uncertain criteria values, $\widetilde{d}_{i k}$, are TrFNs, such as

$$
\widetilde{d}_{i k}=\widetilde{w}_{k} \cdot \widetilde{r}_{i k}
$$

where

$$
\widetilde{d}_{i k}=\left(y ; l_{k} \cdot l_{i k}, m_{k} \cdot r_{i k}, n_{k} \cdot n_{i k}, u_{k} \cdot u_{i k}\right) .
$$

It is possible to express approximated values of fuzzy operations as TrFNs.

3.5. The Selection of the Best Location. The selection of the best location for the construction of above ground parking garage is based on an adaptation of Hurwitz approach for selecting a combined optimistic-pessimistic solution [33] by using the expression:

$$
\max _{i=1, \ldots, I}\left\{\alpha \cdot \min _{k=1, \ldots, K} d_{i k}+(1-\alpha) \cdot \max _{k=1, \ldots, K} d_{i k}\right\},
$$

where $d_{i k}$ presents the representative scalar of $\operatorname{TrFN} \widetilde{d_{i k}}, i=$ $1, \ldots, I ; k=1, \ldots, K$.

The chosen location, $i^{*}$, is the best-compromise location where above ground parking garage should be built, providing that its best criteria value has to be very high, and at the same time, its weakest criteria value must not be bad.

The optimism-pessimism coefficient is denoted as $\alpha$, and it belongs to interval [0-1]. When the value of coefficient of 1 is assigned to the best criterion value and value 0 to all others, then the maximum optimism is expressed. In this case, the max-max policy is selected. If the coefficient of 1 is associated with the worst criterion value and coefficient value 0 to all others, it corresponds to the maximum pessimism, where selected policy is max-min.

\section{Illustrative Example}

The proposed model is tested on the real life data which come from public communal enterprise "Parking Servis Kragujevac" which is established by the local government. The management and improvement of stationary transport represent the most important management sectors in this enterprise. During the last few years, the significance of stationary transport management in urban areas is growing because of the increasing number of inhabitants (ca. half a million gravitate to this city), increasing mobility of the population, increasing number of different activities located in the city center (this is related to culture institutions and events, schools, university, medical center, institutions of executive authority, etc.), changes in the style of living, and so forth. It can be concluded that building of above ground parking garage presents the optimal solution for the treated problem.

The management team has been analyzing four existing parking areas as potential locations that may be used for construction of above ground parking garage with respect to the existing urbanistic plans of the city and results of the research [31]. There are four existing parking lots as potential locations: parking lot $(i=1)$ located near industrial zone and customs, parking lot $(i=2)$ located near administrative business center, parking lot $(i=3)$ located near clinical center, and parking lot $(i=4)$ located near trade centers, catering facilities, and objects of local city government.

The considered parking lots have been assessed with respect to criteria which are defined in Jelokhani-Niaraki and Malczewski [31]. These criteria are discussed in Section 3.2 of this paper.

The fuzzy rating of evaluation criteria is stated by the fuzzy pairwise comparison matrix:

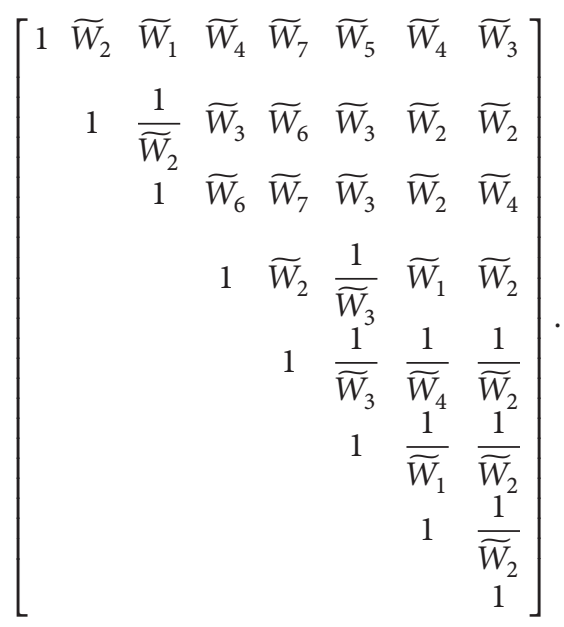

The correctness of the performed assessment of relative importance of evaluation criteria is delivered by using the following procedure. The fuzzy pairwise comparison matrix of the relative importance of evaluation criteria is given by 
using defuzzification procedure [8] and suggestions by Saaty [4]:

$$
\left[\begin{array}{cccccccc}
1 & 2.5 & 1.36 & 5 & 8.56 & 6.5 & 5 & 3.5 \\
0.4 & 1 & 0.431 & 3.5 & 7 & 3.5 & 2.5 & 2.5 \\
0.735 & 2.32 & 1 & 7 & 8.56 & 3.5 & 2.5 & 5 \\
0.2 & 0.286 & 0.143 & 1 & 2.5 & 0.296 & 1.36 & 2.5 \\
0.117 & 0.143 & 0.117 & 0.4 & 1 & 0.296 & 0.204 & 0.296 \\
0.154 & 0.286 & 0.286 & 3.378 & 3.378 & 1 & 0.732 & 0.431 \\
0.2 & 0.4 & 0.4 & 0.735 & 4.902 & 1.366 & 1 & 0.431 \\
0.286 & 0.4 & 0.2 & 0.4 & 3.378 & 2.32 & 2.32 & 1
\end{array}\right] .
$$

The consistency index (CI) is calculated by EM [4] and it is 0.0988 . With respect to the obtained values of CI, it may be concluded that fuzzy rating of management team of the relative importance of criteria can be accepted as correct enough so that further procedure may be performed. The calculation of criteria weights is based on the constructed fuzzy pairwise comparison matrix of the relative importance of criteria whose elements are reciprocity compared to the main diagonal.

The criteria weights are given by using geometric mean operator [22]. This procedure is illustrated with the example of second criteria weight's calculation. By applying (2), it is given that

$$
\begin{aligned}
\alpha_{2} & =\left[\prod_{k=1}^{8} 0.29 \cdot 1 \cdot 0.29 \cdot 2.5 \cdot 7 \cdot 2.5 \cdot 1.5 \cdot 1.5\right]^{1 / 8} \\
& =1.30 \\
\beta_{2} & =\left[\prod_{k=1}^{8} 0.33 \cdot 1 \cdot 0.33 \cdot 3 \cdot 7.5 \cdot 3 \cdot 2 \cdot 2\right]^{1 / 8}=1.53 \\
\chi_{2} & =\left[\prod_{k=1}^{8} 0.5 \cdot 1 \cdot 0.5 \cdot 4 \cdot 8.5 \cdot 4 \cdot 3 \cdot 3\right]^{1 / 8}=2.05 \\
\delta_{2} & =\left[\prod_{k=1}^{8} 0.67 \cdot 1 \cdot 0.67 \cdot 4.5 \cdot 9 \cdot 4.5 \cdot 3.5 \cdot 3.5\right]^{1 / 8} \\
& =2.37 \\
\alpha & =\sum_{k=1}^{8} \delta_{k} \alpha_{k}=2.68 \\
\chi & =\sum_{k=1}^{8} \beta_{k}=2.98 \\
\chi & \sum_{k=1}^{8} \chi_{k}=3.46
\end{aligned}
$$

By using (3), the weight of the second criterion is calculated:

$$
\begin{aligned}
\widetilde{w}_{2} & =(1.30 \cdot 4.08,1.53 \cdot 3.46,2.05 \cdot 2.98,2.37 \cdot 2.68) \\
& =(0.09,0.13,0.21,0.28) .
\end{aligned}
$$

Similarly, weights of the remaining evaluation criteria are calculated and presented as follows:

$$
\begin{aligned}
& \widetilde{w}_{1}=(0.19,0.24,0.35,0.48), \\
& \widetilde{w}_{3}=(0.15,0.22,0.32,0.41), \\
& \widetilde{w}_{4}=(0.03,0.04,0.06,0.09), \\
& \widetilde{w}_{5}=(0.01,0.02,0.03,0.04), \\
& \widetilde{w}_{6}=(0.04,0.05,0.08,0.11), \\
& \widetilde{w}_{7}=(0.04,0.05,0.08,0.12), \\
& \widetilde{w}_{8}=(0.04,0.06,0.09,0.14) .
\end{aligned}
$$

The values of the treated criteria are determined in different ways. For example, adjacent population to a candidate site value $(k=1)$ for the part of the city where parking lot is located $i, i=1, \ldots, I$, is obtained based on the results of the last citizen's survey, the data of which is stored in the database of the local government. Land size $(k=2)$ of each parking lot is determined by urbanistic plan of the city, so its measure is $\mathrm{m}^{2}$. Land cost $(k=3)$ is determined based on the data of local government's body and it is presented in monetary units. Distance to roads from each parking lot can be easily determined by measuring and this unit is presented in meters. Measured and normalized crisp criteria values are obtained by using (6) and (7) (Table 1).

As in the treated city, there are a significant number of recreation centers $(k=5)$, administrative centers $(k=$ $6)$, commercial centers $(k=7)$ which are dislocated, and transportation stations $(k=8)$, and there is an assumption that values of the named criteria are based on the survey delivered by the management team of the public communal enterprise. Customers that have been using all four parking lots have participated in the survey. With respect to their own experience, customers have assessed the last four criteria. Customers who participated in the survey have been chosen randomly without repeating. The representative specimen consists of 100 customers. The results of survey for each treated parking lot are presented in Tables 2, 3, 4, and 5.

The aggregated value of each criterion for each parking lot is calculated by using (10) and illustrated by the following example:

$$
\begin{aligned}
\widetilde{r}_{15} & =\frac{1}{100} \cdot\{5 \cdot(0,0.1,0.15)+10 \cdot(0.15,0.3,0.45) \\
& +70 \cdot(0.35,0.5,0.65)+10 \cdot(0.55,0.7,0.85)+5 \\
& \cdot(0.75,1,1)\}=(0.35,0.45,0.48,0.59) .
\end{aligned}
$$

The normalized aggregated criteria values for each parking lot are calculated in similar way. 
TABLE 1: Measured and normalized crisp criteria values.

\begin{tabular}{lccccccc}
\hline & $v_{i 1}$ & $v_{i 2}$ & $v_{i 3}$ & $v_{i 4}$ & $r_{i 1}$ & $r_{i 2}$ & $r_{i 3}$ \\
\hline$i=1$ & 1830 & 1100 & 500 & 50 & 0.68 & 0.84 & 0.12 \\
$i=2$ & 1532 & 550 & 275 & 200 & 0.57 & 0.42 & 0.37 \\
$i=3$ & 1112 & 420 & 231 & 300 & 0.41 & 0.32 & 0.24 \\
$i=4$ & 620 & 200 & 70 & 20 & 0.23 & 0.15 & 0.28 \\
\hline
\end{tabular}

TABLE 2: Results of survey for parking lot $(i=1)$.

\begin{tabular}{lcccc}
\hline & $k=5$ & $k=6$ & $k=7$ & $k=8$ \\
\hline Very low & 5 & - & - & - \\
Low & 10 & 15 & 8 & 10 \\
Moderate & 70 & 65 & 10 & 72 \\
High & 10 & 20 & 80 & 10 \\
Very high & 5 & - & 2 & 8 \\
\hline
\end{tabular}

TABLE 3: Results of survey for parking lot $(i=2)$.

\begin{tabular}{lcccc}
\hline & $k=5$ & $k=6$ & $k=7$ & $k=8$ \\
\hline Very low & - & - & 5 & 30 \\
Low & 10 & - & 5 & 60 \\
Moderate & 5 & - & 20 & 10 \\
High & 80 & 10 & 60 & - \\
Very high & 5 & 90 & 10 & - \\
\hline
\end{tabular}

TABLE 4: Results of survey for parking lot $(i=3)$.

\begin{tabular}{lcccc}
\hline & $k=5$ & $k=6$ & $k=7$ & $k=8$ \\
\hline Very low & - & - & 4 & 17 \\
Low & 10 & 10 & 22 & 73 \\
Moderate & 20 & 10 & 4 & 10 \\
High & 30 & 70 & 62 & - \\
Very high & 40 & 10 & 8 & -
\end{tabular}

TABLE 5: Results of survey for parking lot $(i=4)$.

\begin{tabular}{lcccc}
\hline & $k=5$ & $k=6$ & $k=7$ & $k=8$ \\
\hline Very low & 78 & 82 & 40 & 5 \\
Low & 22 & 13 & 50 & 20 \\
Moderate & - & 5 & 10 & 50 \\
High & - & - & - & 20 \\
Very high & - & - & - & 5 \\
\hline
\end{tabular}

By using (8) and (11), the weighted normalized criteria values are given and the fuzzy decision matrix (according to (5)) can be stated and presented in Table 6.

The maximum optimism in decision making process is presented. Under this assumption, the best location where above ground parking garage can be constructed is obtained by using max-max policy:

$$
\begin{aligned}
& \max _{i=1, \ldots, 4}\left\{\max _{k=1, \ldots, 8} d_{i k}\right\}=\max _{i=1, \ldots, 4}\{0.213,0.161,0.126,0.251\} \Longrightarrow \\
& i^{*}=4 .
\end{aligned}
$$

If decision makers form their opinion by maximum pessimism in the treated problem, the best location for construction of above ground parking garage is determined by applying max-min policy:

$$
\begin{aligned}
& \max _{i=1, \ldots, 4}\left\{\min _{k=1, \ldots, 8} d_{i k}\right\}=\max _{i=1, \ldots, 4}\{0.011,0.005,0.004,0.003\} \\
& \quad=0.011 \Longrightarrow \\
& i^{*}=1 .
\end{aligned}
$$

If extreme values of the optimism-pessimism coefficient are not discussed, then the best location is determined by using (13). For example, the best-compromise location, obtained for $\alpha=0.5$, is

$$
\begin{aligned}
& \max _{i=1, \ldots, 4}\left\{0.5 \cdot \min _{k=1, \ldots, 8} d_{i k}+0.5 \cdot \max _{k=1, \ldots, 8} d_{i k}\right\} \\
& \quad=\max _{i=1, \ldots, 4}\{0.112,0.083,0.065,0.127\}=0.127 \Longrightarrow \\
& i^{*}=4 .
\end{aligned}
$$

It is worth mentioning that optimism-pessimism coefficient is striving to pessimism side and increasing its value to even $\alpha=0.9$ the optimal solution is location 4 .

$$
\begin{aligned}
& \max _{i=1, \ldots, 4}\left\{0.9 \cdot \min _{k=1, \ldots, 8} d_{i k}+0.9 \cdot \max _{k=1, \ldots, 8} d_{i k}\right\} \\
& \quad=\max _{i=1, \ldots, 4}\{0.1928,0.1453,0.1138,0.2262\}=0.2262 \Longrightarrow \\
& i^{*}=4 .
\end{aligned}
$$

According to the conducted calculation, the strong suggestion for the decision makers is to choose location 4 .

4.1. Discussion. Based on the obtained results, it may be concluded that when the management team is extremely optimistic, the best location is the parking lot $(i=4)$. On the other hand, when management team is extremely pessimistic, the best location is the parking lot $(i=1)$. It can be concluded 
TABLE 6: The weighted normalized fuzzy decision matrix and representative scalars of elements of constructed fuzzy matrix.

\begin{tabular}{|c|c|c|c|c|}
\hline & $i=1$ & $i=2$ & $i=3$ & $i=4$ \\
\hline$k=1$ & $\begin{array}{c}(0.129,0.162,0.247,0.325) \approx \\
0.213\end{array}$ & $\begin{array}{c}(0.108,0.136,0.167,0.272) \approx \\
0.161\end{array}$ & $\begin{array}{c}(0.078,0.099,0.144,0.197) \\
\approx 0.126\end{array}$ & $\begin{array}{c}(0.044,0.055,0.080,0.110) \\
\approx 0.070\end{array}$ \\
\hline$k=2$ & $\begin{array}{c}(0.075,0.109,0.176,0.234) \approx \\
0.145\end{array}$ & $\begin{array}{c}(0.038,0.054,0.088,0.117) \\
\approx 0.073\end{array}$ & $\begin{array}{c}(0.029,0.041,0.067,0.089) \\
\approx 0.055\end{array}$ & $\begin{array}{c}(0.013,0.019,0.032,0.043) \approx \\
0.026\end{array}$ \\
\hline$k=3$ & $\begin{array}{c}(0.019,0.028,0.041,0.053) \\
\approx 0.035\end{array}$ & $\begin{array}{c}(0.035,0.052,0.075,0.096) \\
\approx 0.064\end{array}$ & $\begin{array}{c}(0.042,0.061,0.089,0.112) \approx \\
0.076\end{array}$ & $\begin{array}{c}(0.138,0.203,0.295,0.378) \\
\approx 0.251\end{array}$ \\
\hline$k=4$ & $\begin{array}{c}(0.011,0.015,0.022,0.033) \approx \\
0.019\end{array}$ & $\begin{array}{c}(0.003,0.004,0.006,0.008) \\
\approx 0.004\end{array}$ & $\begin{array}{c}(0.002,0.002,0.004,0.006) \\
\approx 0.004\end{array}$ & $\begin{array}{c}(0.028,0.037,0.055,0.083) \\
\approx 0.048\end{array}$ \\
\hline$k=5$ & $\begin{array}{c}(0.004,0.009,0.014,0.024) \\
\approx 0.011\end{array}$ & $\begin{array}{c}(0.005,0.031,0.021,0.032) \approx \\
0.024\end{array}$ & $\begin{array}{c}(0.004,0.011,0.020,0.029) \\
\approx 0.011\end{array}$ & $\begin{array}{c}(0.0003,0.0009,0.004 \\
0.009) \approx 0.003\end{array}$ \\
\hline$k=6$ & $\begin{array}{c}(0.014,0.023,0.045,0.073) \\
\approx 0.036\end{array}$ & $\begin{array}{c}(0.029,0.044,0.078,0.108) \\
\approx 0.058\end{array}$ & $\begin{array}{c}(0.020,0.031,0.057,0.089) \\
\approx 0.047\end{array}$ & $\begin{array}{c}(0.001,0.002,0.012,0.024) \\
\approx 0.008\end{array}$ \\
\hline$k=7$ & $\begin{array}{c}(0.020,0.030,0.056,0.096) \\
\approx 0.047\end{array}$ & $\begin{array}{c}(0.019,0.029,0.055,0.093) \\
\approx 0.046\end{array}$ & $\begin{array}{c}(0.017,0.027,0.052,0.089) \approx \\
0.043\end{array}$ & $\begin{array}{c}(0.004,0.007,0.019,0.042) \\
\approx 0.016\end{array}$ \\
\hline$k=8$ & $\begin{array}{c}(0.013,0.026,0.047,0.089) \\
\approx 0.040\end{array}$ & $\begin{array}{c}(0.019,0.035,0.061,0.109) \approx \\
0.052\end{array}$ & $\begin{array}{c}(0.017,0.033,0.058,0.060) \\
\approx 0.045\end{array}$ & $\begin{array}{c}(0.014,0.027,0.050,0.091) \approx \\
0.042\end{array}$ \\
\hline
\end{tabular}

that the obtained optimal solution is almost unchangeable when the optimistic-pessimistic coefficient is changed. Based on the obtained results, the rank is stable.

In order to minimise cost and maximise the effectiveness of the decision making process, it is necessary to employ adequate mathematical models.

Comparing papers which propose a model for selecting the best locations under uncertainties, it can be concluded that there are many differences between them and the proposed model in this paper. These differences are briefly presented.

In numerous papers which can be found in the literature, it is assumed that the weight determination of criteria is more reliable when obtained using pairwise comparison $[9,10,17]$ than when they are directly obtained, because it is easier to make a comparison between two criteria than make an overall weight assignment. The procedure for consistency check of constructed fuzzy pairwise comparison matrix of the relative importance of criteria has been determined. It represents one of the main differences between this and the mentioned papers.

In this paper, determining criteria weights are calculated by using the method which is developed in Wu et al. [22]. In this case, criteria weights are described by fuzzy numbers which is more suitable for decision makers compared to other papers where similar criteria weights are described by crisp values $[10,17]$.

The authors of the considered papers have assumed that all considered criteria are uncertain. In practice, such a supposition cannot be taken as completely suitable. In this paper, an effort is given to observe simultaneously both crisp and uncertain criteria in the problem of location selection.

In this paper, method based on Hurwitz criterion [33] has been proposed to deal with multicriteria selection of parking lots in the presence of uncertainty.
The comparison of the proposed model to other MCDM models which are considered in this paper is adopted from Dehe and Bamford [34] and summarized in Table 7.

It may be noticed that the proposed model is computationally attractive and transparent to the practitioners who need a suitable method to real-world problems where values can be either crisp or uncertain. These features of the proposed model represent at the same time its advantage over other similar multicriteria decision models for solving of location selection problems.

\section{Conclusions}

Population growth, fast growing urbanization, and developing industry in the cities lead to scarcity of parking space. Quality of the considered problem is propagated to effectiveness of large number of employees within different organizations, effectiveness of city government, and, above all, the quality of life of citizens [35]. Improvement of stationary transport can be achieved by construction of above or underground parking garages. Application of this solution demands financial support by the local government. In developing countries, the lack of financial resources of the local government represents the main problem for adequate solution of the treated issue over time. Under this constraint, improvement of stationary transport could be solved partially.

Based on the results of good practice, the selection of parking lots where above ground parking garage could be constructed depends on many various criteria. It is assumed that application of analytic methods in selection of the existing parking lots is better than applying intuitive decision making methods. It may be suggested that each solution obtained in an exact way is less encumbered by the subjective views of the decision makers so this could make it more accurate. 
TABLE 7: The comparison among the proposed model and the previous developed MCDM models.

\begin{tabular}{|c|c|c|c|c|c|c|}
\hline & & $\begin{array}{c}\text { Kahraman et al., } \\
2003\end{array}$ & Yong, 2006 & $\begin{array}{c}\text { Ertuğrul, and } \\
\text { Karakaşoğlu, } 2008\end{array}$ & Ćurčić et al., 2011 & $\begin{array}{l}\text { The proposed } \\
\text { model }\end{array}$ \\
\hline \multicolumn{7}{|l|}{ Weighting } \\
\hline & Level & Criteria & Criteria & Criteria & Criteria & Criteria \\
\hline & Method & $\begin{array}{l}\text { Fuzzy pairwise } \\
\text { comparison by } \\
\text { TFNs [20] }\end{array}$ & $\begin{array}{c}\text { Fuzzy group } \\
\text { decision making }\end{array}$ & $\begin{array}{c}\text { Fuzzy pairwise } \\
\text { comparison by } \\
\text { TFNs [20]; } \\
\text { fuzzy group decision } \\
\text { making }\end{array}$ & $\begin{array}{l}\text { Fuzzy pairwise } \\
\text { comparison by } \\
\text { TFNs [20] }\end{array}$ & $\begin{array}{c}\text { Fuzzy pairwise } \\
\text { comparison by } \\
\text { TrFNs [22] }\end{array}$ \\
\hline
\end{tabular}

\begin{tabular}{lccccc}
\hline $\begin{array}{l}\text { Alternative } \\
\text { assessment }\end{array}$ & Method & $\begin{array}{c}\text { Fuzzy pairwise } \\
\text { comparison [20] }\end{array}$ & $\begin{array}{c}\text { Fuzzy group } \\
\text { decision making; } \\
\text { TOPSIS }\end{array}$ & $\begin{array}{c}\text { Fuzzy pairwise } \\
\text { comparison [20]; } \\
\text { TOPSIS }\end{array}$ & $\begin{array}{c}\text { Hurwitz criteria } \\
\text { forzing rating by } \\
\text { fuzzified Hurwitz }\end{array}$ \\
\hline $\begin{array}{l}\text { Results analysis } \\
\text { process }\end{array}$ & $\begin{array}{c}\text { Determined } \\
\text { priority }\end{array}$ & $\begin{array}{c}\text { Determined } \\
\text { priority }\end{array}$ & $\begin{array}{c}\text { Determined } \\
\text { priority }\end{array}$ & $\begin{array}{c}\text { Determined priority } \\
\text { Determined priority }\end{array}$ & $\begin{array}{c}\text { Determined } \\
\text { priority }\end{array}$ \\
\hline
\end{tabular}

The concept of fuzziness is worth regarding selection of the existing parking lots in the cases where some criteria values and the criteria relative importance are uncertain in the linguistic terms. Modelling of used linguistic variable is based on the fuzzy sets theory which is easy to understand and flexible and it is tolerant to imprecise data. Vague linguistic expressions are described by TrFNs.

The main contributions of the proposed model are further discussed: the fuzzy AHP framework is used for the rating of relative importance of evaluation criteria. Handling of uncertain and imprecise data is based on using geometric means that enables making full advantage of the fuzzy sets theory. Then, the proposed adopted Hurwitz approach is used for evaluation and selection of the best parking lots, where the above ground parking garage could be constructed, in terms of quantitive and qualitative evaluation criteria based on different optimistic-pessimistic coefficient values. The proposed model is verified with respect to real life data. It is shown that there is a lot of agreement between the results obtained by applying the proposed model and the project implemented in cooperation of city administration and the management team of the treated enterprise. All the changes, in the relative importance of evaluation criteria, or the number of alternative and fuzzy number membership functions' shape can be easily incorporated in it.

The management team of the public enterprises can easily apply the proposed model to obtain the best location. By using the proposed model, it is possible to rationalize expenditure of time, money, and other resources which consequently lead to increasing effectiveness of the management team. This can be considered as the main contribution of the proposed model. Also, it can be mentioned that the proposed model can be easily extended to analyze other management decision problems in public enterprises as well as in enterprises of a different economy branch.

Further research besides aforementioned advantages of the proposed model can be extended developing software based on the proposed model.

\section{Conflicts of Interest}

The authors declare that they have no conflicts of interest.

\section{References}

[1] E. Inci, "A review of the economics of parking," Economics of Transportation, vol. 4, no. 1-2, pp. 50-63, 2015.

[2] K. Shaaban and A. Pande, "Classification tree analysis of factors affecting parking choices in Qatar," Case Studies on Transport Policy, vol. 4, no. 2, pp. 88-95, 2016.

[3] J. Figueira, S. Greco, and M. Ehrogott, Multiple Criteria Decision Analysis: State of the Art Surveys, Springer, New York, NY, USA, 2005.

[4] T. L. Saaty, "How to make a decision: the analytic hierarchy process," European Journal of Operational Research, vol. 48, no. 1, pp. 9-26, 1990.

[5] G. Işiklar and G. Büyüközkan, "Using a multi-criteria decision making approach to evaluate mobile phone alternatives," Computer Standards and Interfaces, vol. 29, no. 2, pp. 265-274, 2007.

[6] L. A. Zadeh, "The concept of a linguistic variable and its application to approximate reasoning-I," Information Sciences, vol. 8, no. 3, pp. 199-249, 1975.

[7] H. J. Zimmermann, Fuzzy Set Theory and Its Applications, Kluwer Academic, Boston, Mass, USA, 2001.

[8] G. J. Klir and T. Folger, Fuzzy Sets, Uncertainty, and Information, Prentice Hall, Upper Saddle River, NJ, USA, 1988.

[9] F. Torfi, R. Z. Farahani, and S. Rezapour, "Fuzzy AHP to determine the relative weights of evaluation criteria and Fuzzy TOPSIS to rank the alternatives," Applied Soft Computing Journal, vol. 10, no. 2, pp. 520-528, 2010.

[10] T. Kaya and C. Kahraman, "Multicriteria decision making in energy planning using a modified fuzzy TOPSIS methodology," Expert Systems with Applications, vol. 38, no. 6, pp. 6577-6585, 2011.

[11] S. Sadi-Nezhad and K. K. Damghani, "Application of a fuzzy TOPSIS method base on modified preference ratio and fuzzy distance measurement in assessment of traffic police centers performance," Applied Soft Computing Journal, vol. 10, no. 4, pp. 1028-1039, 2010. 
[12] S. Arsovski, G. Putnik, Z. Arsovski et al., "Modelling and enhancement of organizational resilience potential in process industry smes," Sustainability, vol. 7, no. 12, pp. 16483-16497, 2015.

[13] C. T. Chen, C. T. Lin, and S. F. Huang, "A fuzzy approach for supplier evaluation and selection in supply chain management," International Journal of Production Economics, vol. 102, no. 2, pp. 289-301, 2006.

[14] A. Kelemenis and D. Askounis, "A new TOPSIS-based multicriteria approach to personnel selection," Expert Systems with Applications, vol. 37, no. 7, pp. 4999-5008, 2010.

[15] D. Yong, "Plant location selection based on fuzzy TOPSIS," International Journal of Advanced Manufacturing Technology, vol. 28, no. 7-8, pp. 839-844, 2006.

[16] I. Ertuğrul and N. Karakaşoğlu, "Comparison of fuzzy AHP and fuzzy TOPSIS methods for facility location selection," International Journal of Advanced Manufacturing Technology, vol. 39, no. 7-8, pp. 783-795, 2008.

[17] D. Tadić, A. T. Gumus, S. Arsovski, A. Aleksic, and M. Stefanovic, "An evaluation of quality goals by using fuzzy AHP and fuzzy TOPSIS methodology," Journal of Intelligent \& Fuzzy Systems, vol. 25, no. 3, pp. 547-556, 2013.

[18] D. Tadić, A. Aleksić, M. Stefanović, and S. Arsovski, "Evaluation and ranking of organizational resilience factors by using a twostep fuzzy AHP and fuzzy TOPSIS," Mathematical Problems in Engineering, vol. 2014, Article ID 418085, 13 pages, 2014.

[19] I. Macuzić, D. Tadić, A. Aleksić, and M. Stefanović, "A two step fuzzy model for the assessment and ranking of organizational resilience factors in the process industry," Journal of Loss Prevention in the Process Industries, vol. 40, pp. 122-130, 2016.

[20] D. Chang, "Applications of the extent analysis method on fuzzy AHP," European Journal of Operational Research, vol. 95, no. 3, pp. 649-655, 1996.

[21] G. Büyüközkan, O. Feyzioğlu, and E. Nebol, "Selection of the strategic alliance partner in logistics value chain," International Journal of Production Economics, vol. 113, no. 1, pp. 148-158, 2008.

[22] X. Wu, F. Pu, S. Shao, and J. Fang, “Trapezoidal fuzzy AHP for the comprehensive evaluation of highway network programming schemes in Yangtze river delta," in Proceedings of the Fifth World Congress on Intelligent Control and Automation, WCICA 2004, pp. 5232-5236, June 2004.

[23] C. Kahraman, D. Ruan, and I. Doğan, "Fuzzy group decisionmaking for facility location selection," Information Sciences, vol. 157, no. 1-4, pp. 135-153, 2003.

[24] J. Yang and H. Lee, "An AHP decision model for facility location selection," Facilities, vol. 15, no. 9-10, pp. 241-254, 1997.

[25] S. T. Ponis, S. P. Gayialis, I. P. Tatsiopoulos, N. A. Panayiotou, D.-R. I. Stamatiou, and A. C. Ntalla, "An application of AHP in the development process of a supply chain reference model focusing on demand variability," Operational Research, vol. 15, no. 3, pp. 337-357, 2014.

[26] R. Petrovic and D. Petrovic, "Multicriteria ranking of inventory replenishment policies in the presence of uncertainty in customer demand," International Journal of Production Economics, vol. 71, no. 1-3, pp. 439-446, 2001.

[27] S. Petrovic and R. Petrovic, "A new fuzzy multi-criteria methodology for ranking of alternatives," International Transactions in Operational Research, vol. 9, no. 1, pp. 73-84, 2002.

[28] S. Ćurčić, D. Tadić, M. Pavlović, S. Arsovski, and S. Milunović, "Fuzzy multi-criteria model for selecting the best location for a regional landfill," Revisa de Chimie, vol. 62, no. 88, pp. 761-852, 2011.

[29] H.-S. Shih, H.-J. Shyur, and E. S. Lee, "An extension of TOPSIS for group decision making," Mathematical and Computer Modelling, vol. 45, no. 7-8, pp. 801-813, 2007.

[30] V. X. Tran, H. Tsuji, and R. Masuda, "A new QoS ontology and its QoS-based ranking algorithm for Web services," Simulation Modelling Practice and Theory, vol. 17, no. 8, pp. 1378-1398, 2009.

[31] M. Jelokhani-Niaraki and J. Malczewski, "A group multicriteria spatial decision support system for parking site selection problem: a case study," Land Use Policy, vol. 42, pp. 492-508, 2015.

[32] J. C. Pomerol and S. Barba-Romeo, Multicriteria Decision Management: Principles and Practice, Kluwer Nijhoff Publishing, Boston, Mass, USA, 2000.

[33] J. D. Hey, Uncertainty in Micro-Economics, Martin Robertson, Oxford, UK, 1979.

[34] B. Dehe and D. Bamford, "Development, test and comparison of two Multiple Criteria Decision Analysis (MCDA) models: a case of healthcare infrastructure location," Expert Systems with Applications, vol. 42, no. 19, pp. 6717-6727, 2015.

[35] F. Fonseca, S. Pinto, and C. Brito, "Service quality and customer satisfaction in public transports," International Journal for Quality Research, vol. 4, no. 2, pp. 125-130, 2010. 


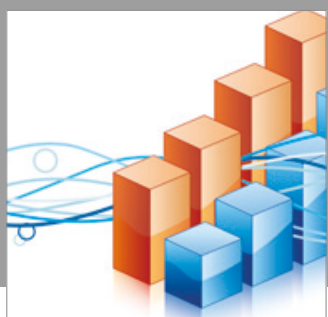

Advances in

Operations Research

vatersals

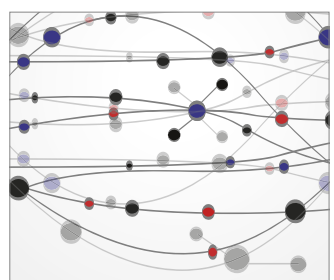

\section{The Scientific} World Journal
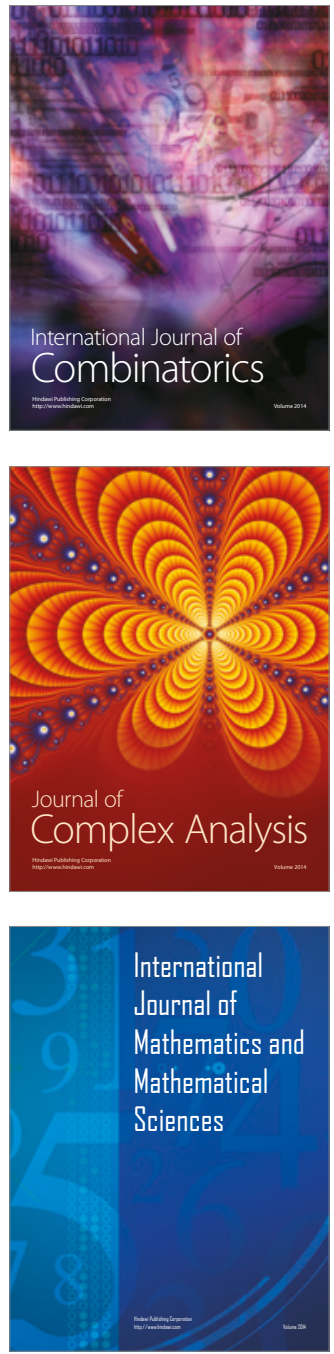
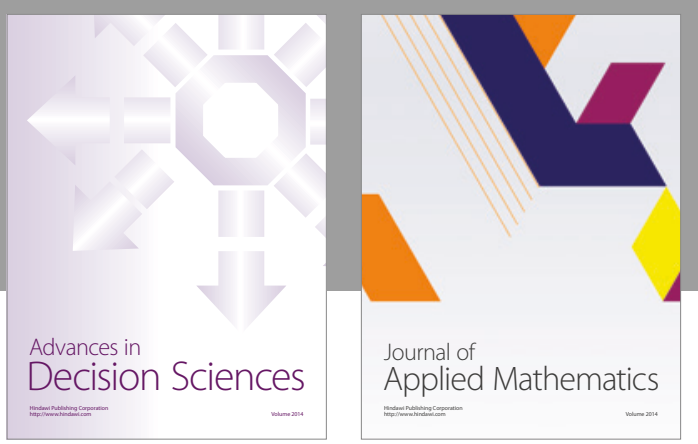

Algebra

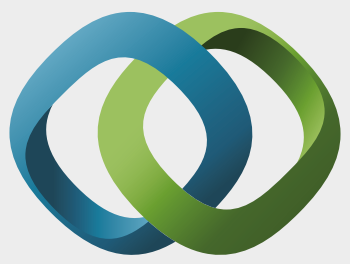

\section{Hindawi}

Submit your manuscripts at

https://www.hindawi.com
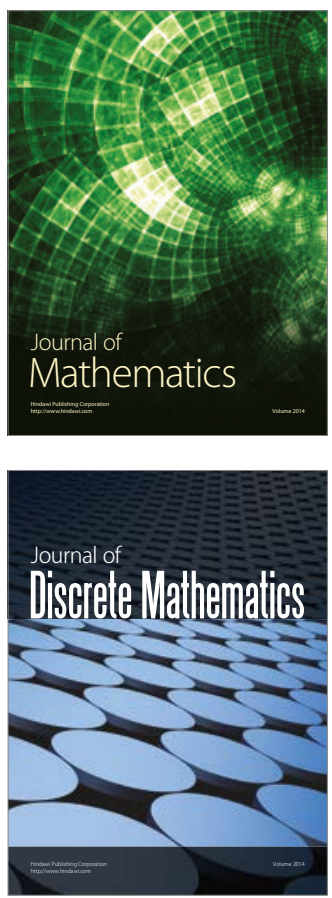

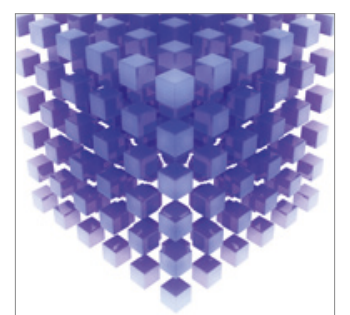

Mathematical Problems in Engineering
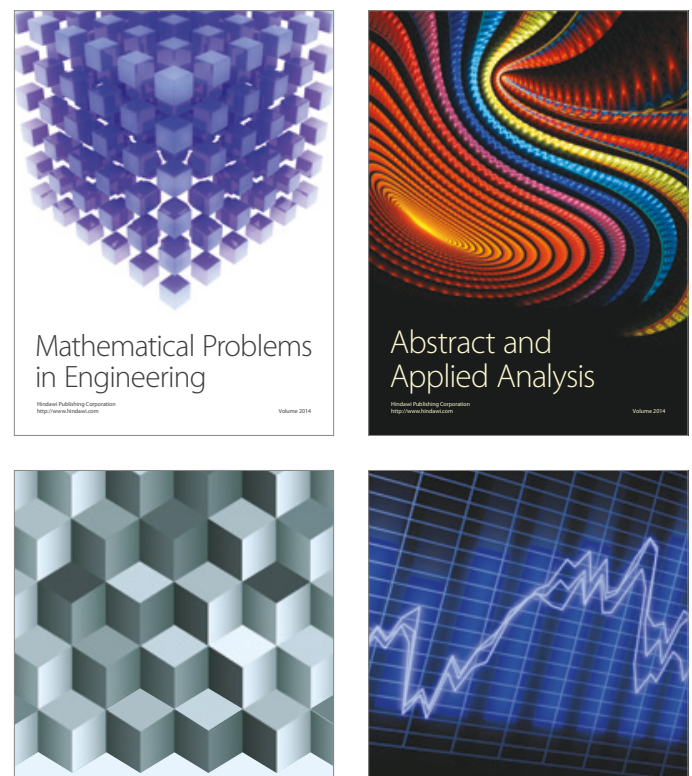

Journal of

Function Spaces

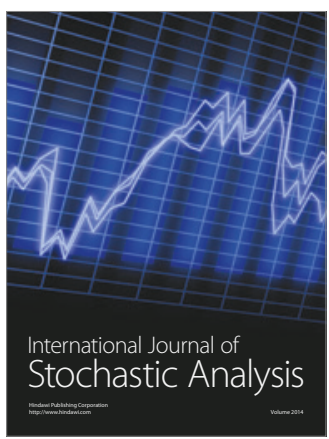

Probability and Statistics
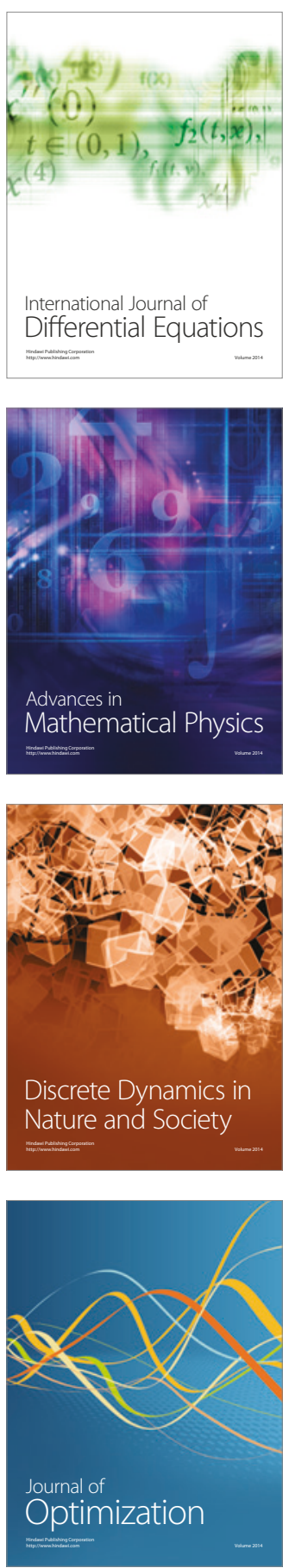